\title{
Application of ANN in prediction of response parameters in CNC Turning
}

\author{
Raman Kumar ${ }^{1}$, Jasgurpreet Singh Chohan ${ }^{1 *}$, Sandeep Singh $^{2}$, Jatinder Kaur $^{3}$ \\ ${ }^{1}$ Department of Mechanical Engineering, Chandigarh University, Punjab-140413, India \\ ${ }^{2}$ Department of Civil Engineering, Chandigarh University, Punjab-140413, India \\ ${ }^{3}$ Department of Electronics and Communication Engineering, Chandigarh University, Punjab-140413, India
}

\begin{abstract}
Product surface quality material removal rate play a great role in the current manufacturing industry. The use of artificial intelligence becomes immensely important component in research work. . In today advanced technology era, the use of $\mathrm{CNC}$ in lathe is common and essential to enhance the productivity of manufacturing industry. In this research work, the application of artificial neural network has been shown to predict the values of surface finish and MRR during turning operation on a CNC lathe machine. The association between process variables and response variables through hidden layers has been presented. The experimental data set was used for training (70\%), testing (15\%) and validation (15\%) of neural network. The measured values are compared with the predicted values and percentage of predicated errors are computed. In present work, a neural network is developed and trained, tested and validated with the help of MATLAB. The study can be beneficial for estimation of surface finish of products during commercialization which would reduce the manufacturing coat and time.
\end{abstract}

\section{Introduction}

Machining process creates a distinctive part shape because of relative motions between the workpiece and cutting tool. In rough cut, higher feed and depth of cut are actually used and therefore poor surface finish is obtained [1]. Additionally, it fails to give higher dimensional accuracy and close tolerance. Finish pass is able to improve finish, tolerance and accuracy as really low feed and level of cut are actually employed. Movement of tool is axially, along the edge of the job, perform cutting to develop various characteristics, which includes contours, chamfer, tapers, and steps [2]. These characteristics are generally machined at a little radial level of several passes and cut are developed to achieve the desired value of diameter [3].

The functioning of rough turning is actually applied to eliminate as much metal as possible in the least length of time. Accuracy and surface finish aren't essential in this particular operation. So, max level of a.020 along with.030 inch to. 030 inch feed is actually highly recommended. Workpiece is usually difficult turned to within approximate 0.030 inch of the finished dimensions in a number of cuts [4].

Finish operation on a lathe that follows rough turning, creates a sleek surface finish, as well as cuts the workpiece to a precise size. Things such as for instance the problem of the cutting tool bit, the rigidity of the printer and workpiece and the lathe speed and feedrate, might have an effect on the kind of surface finish produced [5]. Computer numerical control
(CNC) has been integrated into a selection of innovative technologies and machinery. A CNC lathe is generally created utilizing contemporary variations of carbide tooling and processes CNC Turning is a detailed and intricate technique of making components and custom parts working with a lathe. Computer numerical control $(\mathrm{CNC})$ has been integrated into a selection of innovative technologies and machinery [6]. One particular machine of this kind which is actually applied for a large array of production procedures is actually widely known as a CNC lathe. Because of technological advances, CNC lathes are rapidly changing several of the earlier and much more traditionally used production lathes, like the multispindle.

CNC turning is most commonly used machining process to machine a diametric job at less time with good surface finish [7]. Turning is actually a machining activity in which the workpiece (like a metallic part) is actually turned at a high speed, while a cutting device is actually utilized to cut away the components of the workpiece which are not necessary. The cutting tool doesn't rotate, and it moves in a linear direction only. Turning is generally done on the outside surface area of the workpiece, but at times it's also carried out on the interior. At that time, the procedure is recognized as boring. Similarly, cutting faces on the outside aspect of the workpiece while it's rotating is actually widely known as facing.

A CNC lathe is usually used to achieve optimum response parameters i.e. MRR, surface finish. CAM or 
CAD processes are used to move the machine's tool paths for manufacturing a product. A skilled coder can manually develop a part or perhaps tool path also. The resulting $\mathrm{G}$ Code computer file is then published to the CNC machine, and the device will likely then immediately create the desired areas for what it was programmed to design [8]. There has been considerable progress in the CNC machining industry, especially when it comes to the layout and use of $\mathrm{CNC}$ lathes. Different lathe manufacturers use a bunch of user interfaces that could be a task to the operators. But these methods are mainly dependent on the same concepts across the board since a CNC lathe is actually programmed to do identical features in terms of what it's meant to manufacture. Within the manufacturing sector, the needs of CNC turning operation is actually paramount because industry have to construct complex designs that would not be possible without the help of computer programming. In an assembly, there are huge amounts of components interconnected with each other which also communicate with one another to produce a product [9].

In turning, the workpiece and that is generally rigid and made of plastic, stone, wood, or either metal is actually rotated, while a cutting device is actually moved along the workpiece in three different axes of movements in order to produce accurate depths and diameters. There are mainly four kinds of turning; profiling, external grooving, straight turning, and taper turning [10]. These processes create various kinds of shape from a one-time workpiece like conical, curved, straight or grooved. Turning could be done in either of 2 ways; manually or through the usage of a CNC. In the earlier days, turning was performed by hand and the operator had to always monitor the progression. It was inaccurate and time-consuming. With developments in manufacturing technology and electronics technology, the usage of computer numerical control (CNC) started to be widespread and models built with microcomputers were and are now being applied to carry out turning. In CNC turning, a computer program is actually created by the operator with all of the required dimensions and variables and the file is actually transmitted to the lathe machine. Using stepper motors to manage the cutting tool, the printer automatically produces the very best benefits. It's extremely accurate, supple, as well as faster than performing it by hand [11].

Neurons are the essential component used in processing of a neural networking. This particular foundation of recognition encompasses a couple of basic abilities. Essentially, a biological neuron get signals from various other sources, performs a typically non-linear functioning on the outcome, and then outputs the last outcome. The aim of ANN is not the recreation of the human brain.

\section{Literature Review}

The CNC turning operation is performed on vanadium metal and roughness parameters are discussed. The need of high surface quality and way to achieve the same is presented. Taguchi method was applied on L-9 orthogonal array, the signal-to-noise ratio was computed to investigate the effect of process parameters on surface quality of workpiece. The optimum setting of process parameters viz. cutting feed, depth and speed of cutwere presented to facilitate price reduction as well as product quality enhancement [12]. Surface characteristic of product influences the amount of total satisfaction of the customers during use of the procured items. L'27 orthogonal array was developed for design of experiment and Taguchi method was applied to obtain the optimum setting of independednts parameters viz. cutting velocity, feed rate and depth of cut). The turning operation was performed on EN24 (carbon steel) and Surface roughness is actually investigated [12]. An effort has been made to optimize the CNC machining parameters with the assistance of Taguchi method. The machining operation was carried out on aluminum alloy Al6061. The effect of input parameters viz. cutting velocity, feed, level of cut were investigated on responses variables i.e surface roughness and MRR. The $\mathrm{S} / \mathrm{N}$ ratio technique was used to examine the influence of interdependent parameters. It has been observed that feed fee is dominating parameter which influences the MRR and surface finish while turning of Al6061 [13]. Machining at higher cutting speed, the machine wear get accelerated which influence adversely the machining efficiency and also decrease surface quality of workpiece. In order to fix these issues the various methods of improving the tool life are actually used including cooling the instrument, cryogenic treatment and minimum quantity lubrication. The machining conditions during machining of EN 24 alloy steel were observed in dry \& minimum quantity lubrication conditions. The outcomes of tool use in all of instances have been compared and it has been observed that tool wear is more with dried up machining as compared to MQL.

An attempt has been made to optimize the CNC turning details to obtain the least area roughness on EN 354 alloy steel. Taguchi optimization strategy is implemented on experiment results to enhance cutting details i.e. cutting velocity, feed fee and depth of cut and responses are examined using ANOVA. The experiments have been carried out by using L9 orthogonal array on STALLION 100HS CNC printer and MINITAB 17 application is used. Taguchi approach showed that the cutting velocity is a dominating parameter followed by feed rate in the examination of surface roughness and the depth of cut has least impact on surface roughness [12]. An effort has been made examined the effect of cutting velocity, feed rate, and depth of cut, cutting condition and nose radius on surface roughness in turning operation. The machining of EN24 steel is performed using carbide tool on CNC lathe machine. The settings of process parameters were optimized using the Taguchi's experimental method. Orthogonal arrays, $\mathrm{S} / \mathrm{N}$ ratio and ANOVA method were applied to obtain the optimum level of independent parameters. The results indicated that three process parameters viz. nose radius, cutting Speed and cutting conditions have most significant 
impact on surface roughness. Literature showed that a number of manufacturing methods are available and which are necessary for retaining the position during market competition. Innovation and research in machining is essential to achieve profits. For the manufacturing difficulties, the Taguchi parameter optimization strategy is actually an efficient and powerful tool to achieve desirable quality as well as performance output. The surface characteristics of final product after performing the turning on $\mathrm{CNC}$ lathe has been examined. Three process parameters viz. cutting depth, feed, and speed of cut were considered to enhance the response variables. Orthogonal array L9 was used to perform the experiments using different combination of process parameters level. The $\mathrm{S} / \mathrm{N}$ ratio was computed to present the influence of each process parameters on surface roughness of workpiece [10]. Now a times every manufacturing industries wishes to create quality products that are high with lowest possible cost related to it. The input variables are selected so well that the output effect may be controlled along with high accuracy. The possible main process parameters were identified and discussed their position in achieving the maximum output. A detailed discussion was presented which helps to understand how the input variable impacts the output or maybe response variables. It was stated that the most popular method for process parameter optimization is Taguchi Method. The results of published work were compared to show the significance of ANNOVA and $\mathrm{S} / \mathrm{N}$ ration. A stepwise guidelines were presented to develop orthogonal array and way to measure the surface finish. The significance of MINITAB software were shown in design of experiments [9].

The optimization of machining parameters is essential to enhance the production rate. An experiement study was performed to enhance the surface finish of aluminium-2014 alloy by modifying the machining parameters of $\mathrm{CNC}$ turning, cutting speed, including, level of cut as well as feed fee. Based on L9 orthogonal array, a complete of 9 experiments had been conducted according to Taguchi process with various parameter settings. The surface area roughness of the machined items was assessed by a roughness tester, and additionally evaluated by signal-to-noise ratio (SNR). ANOVA was performed to search for the ideal parameter configurations for area roughness. The results indicated that the cutting speed is regarded as the important parameter $(67.28 \%)$ on area roughness, followed by feed fee $(32.28 \%)$ as well as level of cut $(0.33 \%)$ for area roughness. It was concluded that the outside roughness can easily be enhanced by reducing the feed rate and level of cut [8].

In a manufacturing business, machining procedure is used to manufacturing the metallic parts by removing unwanted content by means of tool. During the machining activity of any portion given quality specifications including surface quality, dimensional accuracy with least production cost or perhaps machining time are actually to be considered. To attain the last area quality as well as dimensional tolerance. Surface quality created by the machining procedures is actually among the essential elements to figure out the useful performance as well as correspondent fatigue life time of the components. The best possible combinations of input parameters viz. cutting speed, feed fee, level of cut, material removal fee, equipment geometry, job piece clamping, material composition, chip formations was found using orthogonal array. A series machining tests had been conducted on the non ferrous components specimen to examine the influence of machining parameters. This results showed that there is correlation between cutting parameters and response parameters [14].

\section{Results and Dsicussions}

Kumar et al. [15] performed an experiment using CNC turning to get the desired values of MRR and surface finish. Orthogonal array L9 was used to perform the experiment using combination of different levels of process parameters. In present work, ANN is developed as shown in figure 1 using 20 hidden layers.

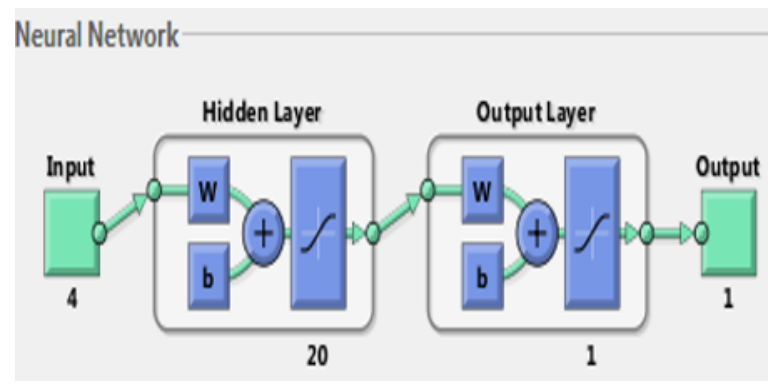

Figure 1 Neural network

Different networks focus on issues in which the resolutions aren't only one of several recognized values. These neurons appear to be able to almost unrestricted interconnections. While generally there are helpful networks which contain just one level, or perhaps one component, many uses need networks that have a minimum of the 3 typical kinds of layers feedback, output, and hidden. The level of neurons get the information possibly from enter documents or even immediately from electric sensors in real time programs. The output level transmits info straight to the external world, to a secondary laptop procedure, or even to various other products like a physical management feature. Between these 2 layers may be several secret layers. Nowadays, developments in biological is to investigate the organic thinking mechanism. The course of action for saving information as patterns, using the patterns, and then solving issues entails a completely new location of computing. This specific region, as mentioned before, doesn't make use of regular programming but consists of the building of incredibly the instructions and parallel networks of the networks to clear up certain issues. This particular area too utilizes words totally distinct from regular computing, words such as behave, generalize, discover, self organize, react, and forget. This particular brain modeling additionally guarantees a significantly less specialized technique to possess printer strategies. 
The output of ANN model is shown in figure 2 (a), 2(b), 2(c) and 2(d). The predicted results of surface finish is presented in Appendix 1.
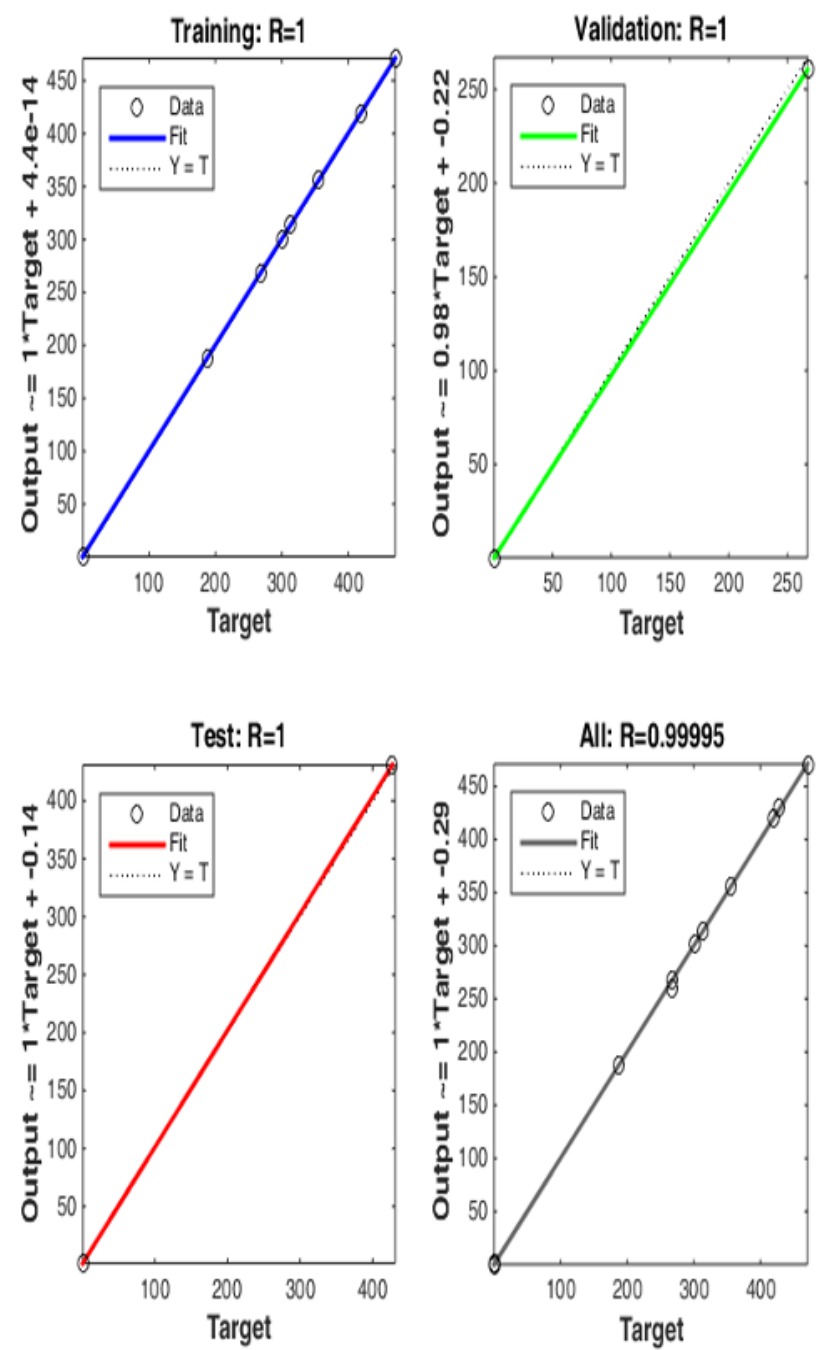

Figure 2(a) Regression analysis of ANN model

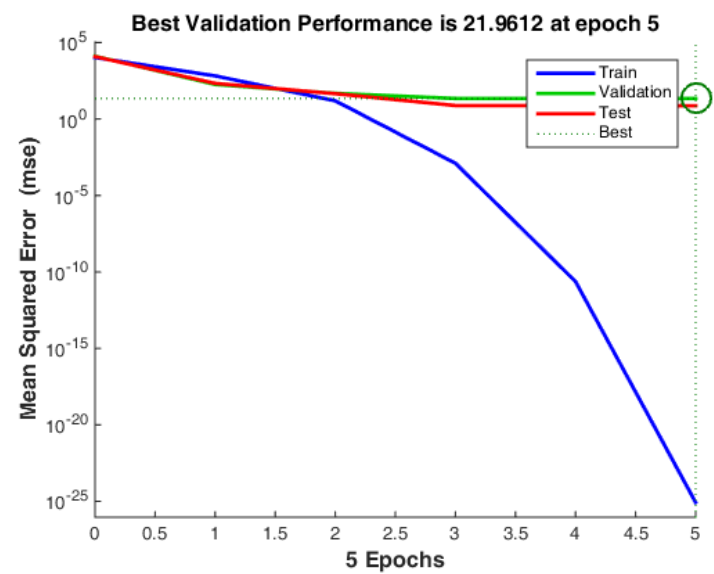

Figure 2 (b) Validation performance of ANN model

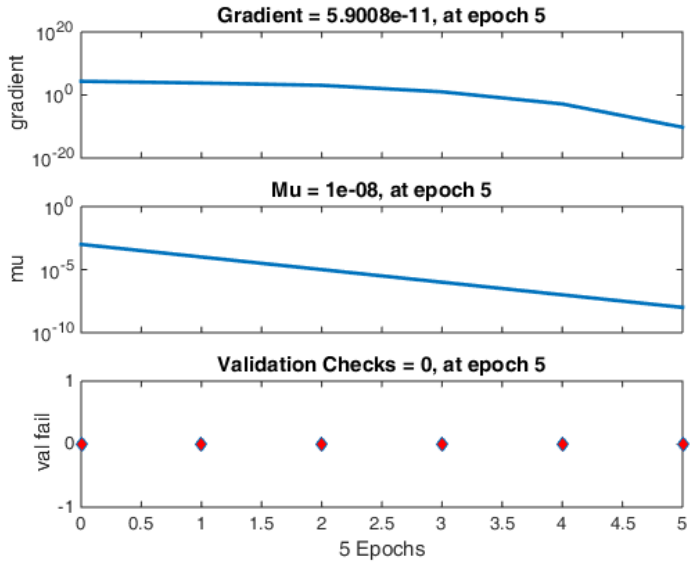

Figure 2(c) Gradient and epoch record

\section{Conclusions:}

The present work show the application of artificial neural network in prediction of response parameters. Three neural network with different hidden layers i.e 10, 15 and 20 were trained with L9 data set. It has been observed that network with 10 hidden layers provided less errors in prediction of response parameters. The regression analysis of trained network showed the value of $\mathrm{R}=1$ and overall value of regression analysis is 0.99995 . The best performance of validation data set is $5.9 \times 10^{-11}$ at epoch 5 . In addition to this, deep learning could be implemented to enhance the accuracy of predicated variables or reduce the percentage prediction error of network.

\section{References:}

1. R. Kumar, J. S. Chohan, R. Goyal, P. Chauhan, Int. J. Struct. Integr. 12, 366 (2021).

2. M. Vijay Kumar, B. J. Kiran Kumar, N. Rudresha, Mater. Today Proc. 5, 11395 (2018).

3. R. Kumar, J. S. Chohan, R. Goyal, P. Chauhan, Int. J. Struct. Integr. 12, 366 (2021).

4. S. Dhanalakshmi, T. Rameshbabu, Metals (Basel). 10, 453 (2020).

5. V. Upadhyay, P. K. Jain, N. K. Mehta, Measurement, 46, 154 (2013).

6. S. Rajesh, D. Devaraj, R. Sudhakara Pandian, S. Rajakarunakaran, Int. J. Adv. Manuf. Technol. 67, 811 (2013).

7. H. Vasudevan, N. C. Deshpande, R. R. Rajguru, Procedia Eng. 97, 85 (2014).

8. A. Arunnath, P. H. S. Masooth, Mater. Today Proc. 45, 6253 (2021).

9. P. Sahoo, M. P. Satpathy, V. K. Singh, A. Bandyopadhyay, World J. Eng. 15, 700 (2018).

10. T. Singh, J. S. Dureja, M. Dogra, M. S. Bhatti, Multidiscip. Model. Mater. Struct. 15, 538 (2019).

11. V. R. Pathapalli, V. R. Basam, S. K. Gudimetta, M. R. Koppula, World J. Eng. 17, 237 (2019). 
12. V. R. Pathapalli, M. R. Reddigari, E. K. Anna, P. Srinivasa Rao, D. V. Ramana Reddy, Multidiscip. Model. Mater. Struct. (2021).

13. R. B. Patil, B. S. Kothavale, L. Y. Waghmode, S. G. Joshi, Int. J. Qual. Reliab. Manag. 34, 1616 (2017).

14. K. Jayakrishna, R. J. Girubha, S. Vinodh, J. Eng. Des. Technol. 14, 422 (2016).

15. R. Kumar, R. Kumar, G. Soni, S. Chhabra, Int. J. Eng. Res. Technol. 2, 3478 (2013).

Appendix I Values of parameters and predicted values

\begin{tabular}{|c|c|c|c|c|c|c|c|c|}
\hline & \multicolumn{5}{|c|}{ Input parameters } & \multicolumn{2}{c|}{ Response parameters } & \multicolumn{2}{c|}{ Error in prediction } \\
\hline SI. NO. & $\begin{array}{c}\text { Speed } \\
(\mathbf{r p m})\end{array}$ & $\begin{array}{c}\text { Feed } \\
(\mathbf{m m} / \mathbf{r e v} .)\end{array}$ & $\begin{array}{c}\text { D.OC } \\
(\mathbf{m m})\end{array}$ & $\begin{array}{c}\text { Nose } \\
\text { radius }\end{array}$ & $\begin{array}{c}\text { Surface } \\
\text { finish }\end{array}$ & surface finish & MRR \\
\hline 1 & 1500 & 0.08 & 0.6 & 0.4 & 1.144 & 188 & $-4.65 \mathrm{E}-13$ & $2.84 \mathrm{E}-14$ \\
\hline 2 & 1500 & 0.1 & 0.8 & 0.8 & 0.936 & 314 & $6.05 \mathrm{E}-13$ & $-5.68 \mathrm{E}-13$ \\
\hline 3 & 1500 & 0.12 & 1 & 1.2 & 0.786 & 471 & $-2.03 \mathrm{E}-13$ & 0 \\
\hline 4 & 1600 & 0.08 & 0.8 & 1.2 & 0.576 & 268 & $1.41 \mathrm{E}-14$ & $-5.68 \mathrm{E}-14$ \\
\hline 5 & 1600 & 0.1 & 1 & 0.4 & 1.082 & 419 & $-2.15 \mathrm{E}-14$ & $-4.55 \mathrm{E}-13$ \\
\hline 6 & 1600 & 0.12 & 0.6 & 0.8 & 0.502 & 301 & $-2.28 \mathrm{E}-14$ & $-1.14 \mathrm{E}-13$ \\
\hline 7 & 1700 & 0.08 & 1 & 0.8 & 0.59 & 356 & $-4.06 \mathrm{E}-14$ & 0 \\
\hline 8 & 1700 & 0.1 & 0.6 & 1.2 & 0.51 & 260.3766 & 0.229551 & 6.623422 \\
\hline 9 & 1700 & 0.12 & 0.8 & 0.4 & 1.09 & 430.8476 & 0.126368 & -3.84757 \\
\hline
\end{tabular}

